\title{
COBERTURAS SEDIMENTARES DO MESOPROTEROZÓICO DO ESTADO DE RORAIMA - AVALIAÇÃO E DISCUSSÃO DE SEU MODO DE OCORRÊNCIA
}

\author{
NELSON JOAQUIM REIS* \& ALBERTINO DE SOUZA CARVALHO**
}

\begin{abstract}
MESOPROTEROZOIC SEDIMENTARY COVERS OF THE STATE OF RORAIMA EVALUATION AND DISCUSSION OF THE MODE OF OCCURRENCE In the last few years new data became available from the Middle Proterozoic sedimentary cover in the southern part of the Guyana Shield. Recent studies in continups exposures of Roraima Supergroup sediments, located in the Pacaraima Block (BP), northern part of the Amazon Craton made possible to interpretate its depositional environments, as well the basin evolution. Nevertheless, in the south of this block there are several large table mountain sequences of similar rocks, disconnected from the main preserved basin, that remain very poor known (Tepequém, Urutanim, Uafaranda and Surucucus Table), wich appear to be outliers of Roraima Supergroup. This paper tries to understand the relationship with both exposures, with emphasis to the environments of deposition and available isotope ages. These proterozoic basins seems to be of multiple age, ranging from 1.7 to 1.4 Ga with gaps of m.y. Associated alluvial deposits are of economic interest due to their gold and diamonds-bearing content.
\end{abstract}

Keywords: Roraima Supergroup, Amazon Craton, Gold, Diamond, Depositional Environment.

RESUMO Os trabalhos geológicos desenvolvidos nos últimos dez anos, em diversas exposições sedimentares do Mesoproterozóico do Escudo das Guianas, notadamente no Estado de Roraima, permitiram avançar no conhecimento estratigráfico, estrutural e paleoambiental destas sequiências. Estas rochas sedimentares têm sido através dos tempos, relacionadas ao Supergrupo Roraima. Neste trabalho são apresentadas, tentativamente, as correlações entre sua maior área de exposição (Bloco Pacaraima) e de outros sítios isolados localizados a sul do bloco, que constituem grandes feições sedimentares de forma tabular, como nas serras Tepequém, Urutanim, Uafaranda e Surucucus. Os dados isotópicos disponíveis indicam idades para estas rochas que variam entre 1.7 e $1.4 \mathrm{Ga}$, fundamentadas na idade dos granitos intrusivos que antecedem a cobertura, seleiras básicas e rochas piroclásticas intercaladas, bem como em granitos mais jovens. $\mathrm{O}$ interesse econômico da unidade repousa na significativa exploração garimpeira para ouro e diamante que ocorrem associados aos depósitos aluvionares.

Palavras-chave: Supergrupo Roraima, Cráton Amazônico, Ambientes de Deposição, Ouro, Diamante.

INTRODUÇÃo Vários sítios de deposição de rochas sedimentares mesoproterozóicas distribuem-se de forma contínua e descontínua no Escudo das Guianas (Fig. 1), onde recebem a denominação genérica de Supergrupo Roraima. No Estado de Roraima, a área de exposição mais expressiva e contínua destas rochas ocorre no seu setor setentrional, representada pelo Bloco Pacaraima (BP). Constitui uma extensa cobertura que engloba, ainda, terrenos da Venezuela e Guiana, e que atinge aproximadamente $73.000 \mathrm{~km}^{2}$ (Gibbs \& Barron 1983, 1993). Afora o BP, ocorrem remanescentes sedimentares isolados, representados pelas serras Tepequém, Urutanim, Uafaranda e Surucucus, que localizam-se na porção ocidental do Estado, numa região de difícil acesso, coberta pela floresta amazônica. Esta cobertura se manifesta morfologicamente por um relevo tabular, com predomínio de mesas de topos planos e altitudes entre 1000 e $3000 \mathrm{~m}$. Numerosas outras mesas, pouco conhecidas e litologicamente semelhantes, ocorrem no norte e noroeste do Estado do Amazonas (Urupi/Pitinga, Rio Novo, Aracá, Neblina, Uneuxi e Padre) e nos países vizinhos.

O termo Roraima (Dalton 1912) tem sido estendido às várias exposições sedimentares cronologicamente correlacionadas do escudo, citando-se dentre muitos autores, as contribuições de Aguerrevere et al. (1939) na introdução do termoformação, na sua subdivisão estratigráfica por Bouman (1959) e Yánez (1972), na sua elevação à categoria de grupo (e.g., Reid 1972; Montalvão et al. 1975) e de supergrupo (Pinheiro et al. 1990). Trabalhos de cunho litoestratigráfico também foram realizados em território brasileiro por Pinheiro et al. (1981), Santos \& D'Antona (1984), Reis et al (1985), Santos (1985) e Borges \& D'Antona (1988). Na Guiana e Venezuela importantes estudos direcionados ao reconhecimento de seu ambiente deposicional foram desenvolvi- dos no BP, respectivamente por Keats (1973) e Ghosh (1977). Em Roraima, sua compartimentação paleoambiental foi realizada por Castro \& Barrocas (1986), Reis et al. (1990) e Pinheiro et al. (1 990) em porção do B P, e por Reis et al. (1991) na serra das Surucucus.

O embasamento da seqüência sedimentar é variável e representado por rochas vulcânicas piroclásticas, por um complexo arranjo de ortognaisses, por rochas supracrustais ou por granitos anorogênicos. Uma discordância litológica basal e erosiva tem sido identificada, sendo que em alguns lugares do $\mathrm{BP}$ não ocorrem os denominados conglomerados basais ( $\mathrm{Pi}$ nheiro et al. 1990).

Tanto no Bloco Pacaraima como nos remanescentes isolados, as rochas sedimentares exibem uma atitude geral em homoclinal de direção NW/EW, usualmente com mergulhos inferiores a $10^{\circ}-20^{\circ}$ para $\mathrm{NE} / \mathrm{N}$, ou constituem amplos braquissinclinais e pequenos anticlinais. As falhas mais comuns são em bloco, geralmente gravitacionais, com ocasional movimentação rotacional, acentuando o mergulho original do acamadamento. Associado às falhas maiores (NE e NW) ocorrem diques de diabásio da unidade Avanavero, que alimentam soleiras básicas pouco diferenciadas. Somente o metamorfismo de soterramento é descrito em alguns locais (Ghosh 1977, Gibbs \& Barron, 1993). O principal efeito é a recristalização da matriz em quartzo intersticial, com conteúdo variável de mica e alguma hematita. Muscovita e rara biotita são minerais detríticos originais, mas podem ser resultado de metamorfismo de contato nas proximidades das intrusivas básicas. Mais importante é o efeito do metamorfismo dinâmico superposto (Episódio K'Mudku /1.2 Ga) a estas rochas, que resulta na milonitização local e no estiramento das estruturas primárias.

* CPRM - Serviço Geológico do Brasil - SUREG/Manaus - Av. André Araújo 2160, Aleixo, CEP: 69060-001 Manaus-AM, Brasil - Fax: (092) 663-5531 e-mail: geremi@internext.com.br

** Departamento de Geociências - Universidade do Amazonas - Av. Gal. Rodrigo O.J.Ramos 3000 - Campus Universitário - CEP: 69.077-000 Manaus-AM, Brasil - Fax: (092) 644-1510/644-2227 


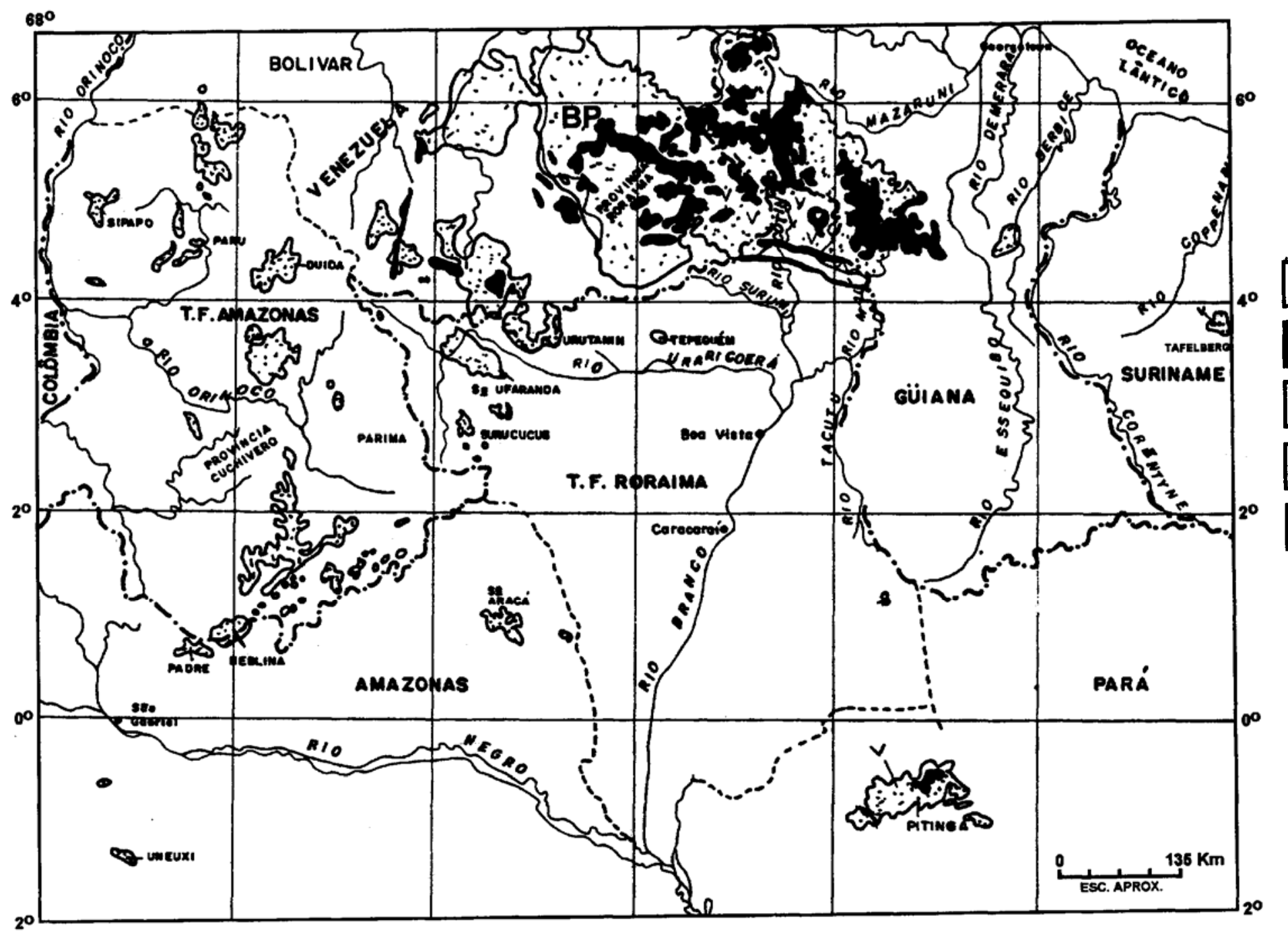

\section{LEGENDA}

$\because$ 1. Rochas sedimentares mesoproterozóicas

2. Rochas básicas Avanavero

3. Limite internacional

‥ 4. Limite Interestadual 5. Rochas piroclásticas

BP - Bloco Pacaraima 
A estas rochas sedimentares proterozóicas relacionam-se inúmeros depósitos secundários de diamante e ouro, os quais vêm sendo explorados por garimpagem desde o início deste século. Estes depósitos derivam do retrabalhamento e reconcentração de fases detríticas pesadas contidas em paleoplaceres, em grande parte nas fácies conglomeráticas das unidades basais. Contudo, concentrações auríferas têm sido identificadas em coberturas terciárias lateritizadas que cobrem as rochas sedimentares, em aluviões delas derivadas (Formação Trincheira - Reis et al. 1985), ou, ainda, associadas a pelitos marinhos (Pinheiro et al. 1990).

DESCRIÇÃO DAS UNIDADES SEDIMENTARES E BACIAS RELACIONADAS A seguir descrevem-se as principais feições estratigráficas, estruturais e litoambientais sob o atual nível do conhecimento das rochas sedimentares do BP e das diversas exposições sedimentares do Mesoproterozóico que ocorrem a sul deste bloco, no Estado de Roraima.

Bloco Pacaraima É a área acerca da qual dispõe-se do maior volume de informações, em grande parte devido à facilidade de acesso e à contribuição dos trabalhos realizados em países vizinhos. No Estado de Roraima, o bloco ocupa grande extensão de seu extremo setentrional, abrangendo continuamente as folhas NB.20-Z-D-II, III e VI, NB.20-Z-BV e VI, NB.21-Y-A e NB.21-Y-C-I e IV. Seu embasamento é constituído por rochas vulcânicas piroclásticas (tufos e brechas) do Grupo Surumu, cujos clastos ocorrem nos níveis mais inferiores da seqüência sedimentar.

A sucessão estratigráfica do pacote sedimentar do Supergrupo Roraima (Pinheiro et al. 1990) é, da base para o topo, representada pela Formação Arai, Grupo Suapi, Formação Uailã e Formação Matauí, atingindo uma espessura total de $2900 \mathrm{~m}$. Quatro níveis de seleiras de rochas básicas da unidade Diabásio Avanavero se intercalam na seqüência sedimentar.

A Formação Arai inclui rochas sedimentares eminentemente continentais (Reis et al. 1990), cujas fácies representam sistemas desérticos (leque aluvial árido, lacustre, dunas eólicas e wadis) e fluvial entrelaçado (Fig. 2). A fácies de leque aluvial árido é proximal e caracteriza-se por paraconglomerados e arenitos conglomeráticos com fragmentos de rocha vulcânica e quartzo leitoso. Os clastos são pouco arredondados, à semelhança de uma sedimentação do tipo fluxo de detritos. Estes gradam lateralmente para quartzo arenitos com estratificação cruzada acanalada (ECA) de pequeno porte $(60,0 \mathrm{~cm})$ e granodecrescência ascendente. Sua geometria revela um padrão de canais fluviais entrelaçados, oriundos de fluxo canalizado na sua porção mais mediana. Em porções distais, a seqüência apresenta uma sucessão de estratos de arenitos finos arcoseanos a discretamente conglomeráticos.

A fácies lacustre está representada pela intercalação de conglomerados com granules e seixos, siltitos micáceos e arenitos finos, em sets rítmicos (Tac de Bouma -inunditos) com estruturas wavy e linsen, flaser, drapes argilosos, laminação planoparalela, marcas onduladas simétricas e gretas de contração.

A fácies eólica e wadis associados é retratada por arenitos arcoseanos e quartzo arenitos médios a finos, extremamente bem selecionados, com estratificações tangenciais de grande porte, com típicas lâminas geradas por fluxo e queda de grãos e superfícies de truncamento. Níveis de canais fluviais temporários estão registrados pela presença de fragmentos de rocha vulcânica, canais estes recobertos por depósitos eólicos. As interdunas possuem estruturas climbing, marcas onduladas, ripples de adesão e laminação planoparalela. Além das lentes de conglomerados intraformacionais, estruturas dish reforçam a deposição rápida e brusca do material sedimentar no aporte dos wadis.

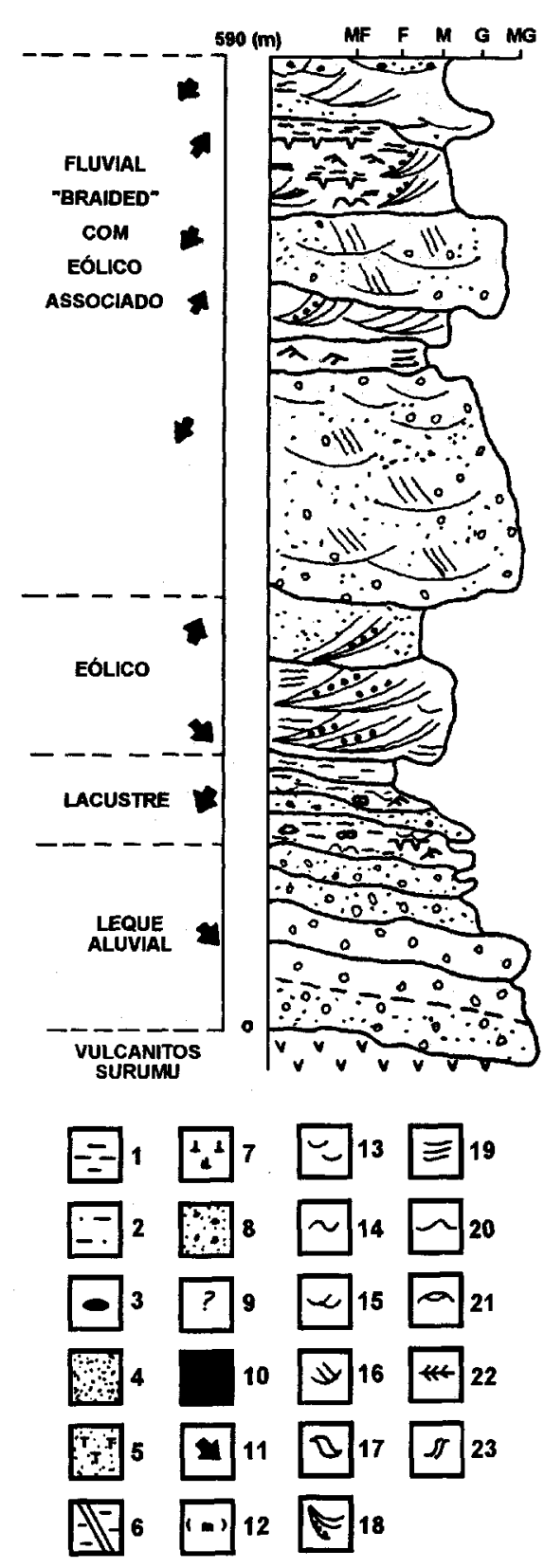

Figura 2 - Seção esquemática da Formação Arai (Reis et al. 1990). Símbolos: 1-argilito, $M F / F ; 2$ - siltito/arenitofino; 3 - siltito carbonoso; 4 - arenitos líticos/quartzo-arenitos, $M / F$; 5 - arenitos tufáceos; 6 -tufos cinerítico ash-fall, $F / M F$; 7 ignimbritos; 8 -arenitos conglomeráticos, $M / G$; 9 - talus; 10 - rocha básica; 11 - direção predominante de paleocorrente; 12 -espessura aproximada; 13 - acamadamento flaser; 14 marca ondulada; 15 - estratificação cruzada acanalada; 16 - estratificação cruzada tabular; 17 - estratificação cruzada sigmoidal; 18 -fluxo/queda de grãos; 19 - laminação planoparalela; 20 -mega-ripples; 21 - hummocky; 22 -heringbone; 23 -fluidização.

Figure 2 - Schematic section of the Arai Formation (Reis et ai. 1990). Symbols: 1 -argilite, MF/F; 2 - siltitelfine arenite; 3 - carbonaceous siltite 4 - lithic arenite/quartz-arenite, $M / F ; 5$ - tuffaceous arenite; 6 -ash-fall tuff, $F / M F ; 7$ - ignimbrite; 8 - conglomeratic arenite, $M / G ; 9$ - talus; 10 - basic rock; 11 - dominant paleocurrent direction; 12 - aproximate thickness; 13 -flaser bedding; 14 - ondulation; 15 - channel cross-bedding; 16 - tabular cross-bedding: 17 - sigmoidal cross-bedding: 18 -flux/grainfall; 19 -plane parallel lamination; 20 -mega-ripples; 21 - hummocky; 22 -heringbone; 23 -fluidization 
A fácies fluvial entrelaçada é composta por arenitos conglomeráticos, conglomerados e quartzo arenitos maciços com níveis centimétricos de arenitos ferruginosos e siltitos subordinados. Um amplo domínio de dunas subaquosas está evidenciado por EC As de grande porte (entre 3,0 a 4,0 m), por vezes festonadas onde entremeiam-se sets com estratificação cruzada tabular (ECT) que denotam barras longitudinais do sistema fluvial. Marcas onduladas assimétricas são comuns na seqüência. Esta fácies se interestratifica localmente com a eólica.

O Grupo Suapi se subdivide, da base para o topo, nas formações Verde, Pauré, Nicarã e Quino, as quais caracterizam diversas transgressões e regressões, evidenciadas através de ambientes transicional (planície de maré e deltaico) e marinho raso (Fig. 3).

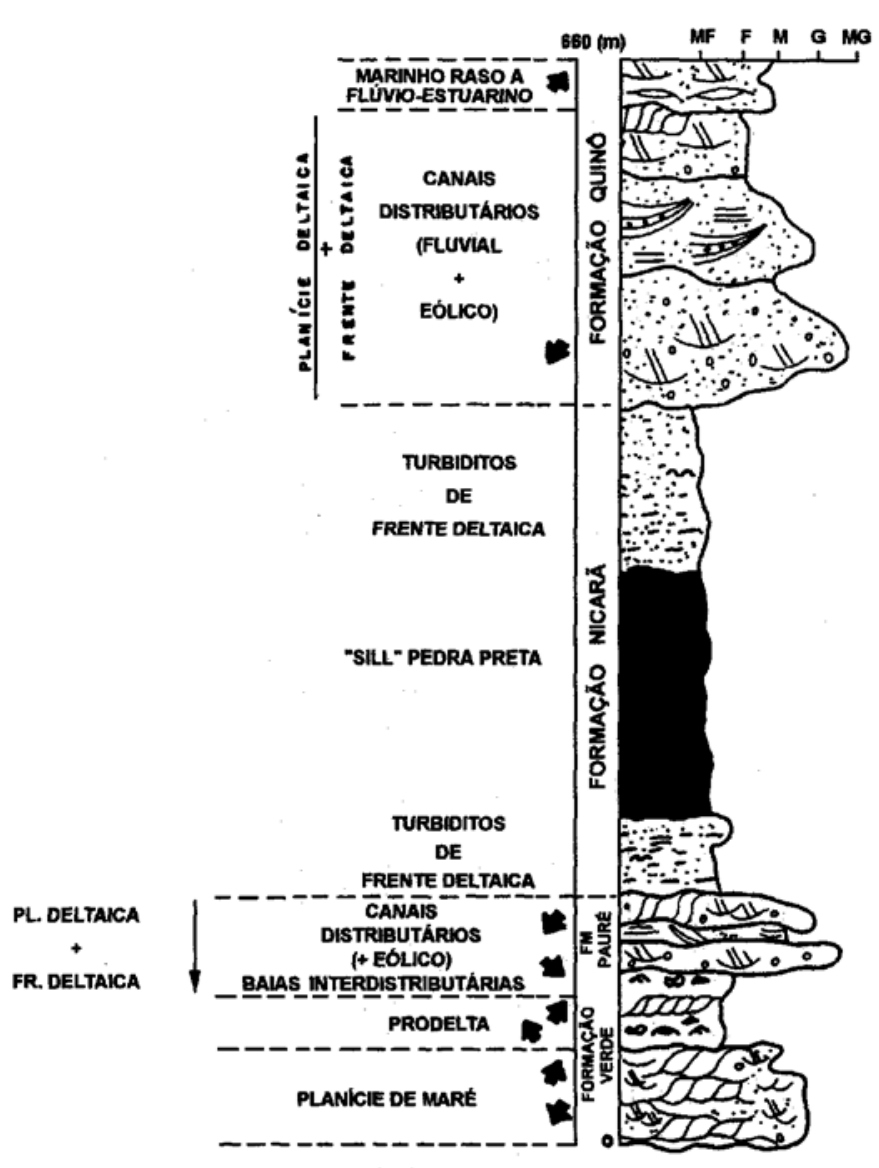

Figura 3 - Seção esquemática do Grupo Suapi e respectivas formações (seg. Reis et al. 1990). Legenda como na figura 2. Figure 3 - Schematic section of the Suapi Group and related formations (Reis et al. 1990). Legend as in figure 2.

A Formação Verde consiste, na base, de arenitos arcoseanos a feldspáticos friáveis que evoluem, para o topo, para uma sucessão de argilitos e siltitos. Os primeiros traduzem uma fácies de planície de maré (inframaré), apresentando bidirecionalidade das EGAs, formas geométricas de lobos sigmoidais, estruturas planares e marcas onduladas simétricas e sinuosas bifurcadas, no topo dos sets. A fácies prodeltaica (argilitos e siltitos) é a transição entre os depósitos distais das barras de foz de canais distributaries e os pelitos de fundo. A fácies de frente deltaica, fluvialmente dominada, compõe-se de ritmitos com laminação planoparalela e climbing-ripples unidirecionais. Os arenitos finos, micáceos, constituem cor- pos sigmoidais amalgamados, com laminação cruzada cavalgante na base, formada por fluxos homopicnais e deposição afastado da desembocadura dos rios. As barras de foz de canais distributários apresentam interestratificação de arenitos finos a muito finos e subordinadamente siltitos, evidenciando franca laminação planoparalela. $\mathrm{O}$ ambiente deltaico deve ter sido construído por uma ativa progradação com término do avanço da frente deltaica síltico-arenosa sobre os pelitos prodeltaicos.

A Formação Pauré é constituída por uma sucessão de arenitos, arenitos conglomeráticos e conglomerados oligomíticos na base, sobrepostos por arenitos arcoseanos e quartzo arenitos maciços, em contato gradacional com à Formação Verde. Interrelacionam-se ao sistema deltaico (fácies de frente e planície deltaica), com criação de novos sistemas fluviais e contribuição decisiva para a implantação de um período regressivo. As direções de paleocorrentes são concordantes com as do sistema fluvial da Formação Arai.

A Formação Nicarã consiste de uma intercalação de siltitos e arenitos finos, laminados e micáceos. São interpretados como ritmitos de frente deltaica turbidítica, representando depósitos de suspensão e apresentando ciclos Tbe de Bouma. Esta unidade assinala novo episódio de transgressão marinha, com afogamento dos sedimentos deltaicos Pauré.

Um ciclo regressivo-transgressivo está representado pelas rochas sedimentares da Formação Quinô. A fácies fluvial entrelaçada é constituída por uma seqüência arenosa conglomerática, com abundantes EGAs e estruturas festonadas em sets com marcante granodecrescência ascendente, secionando os turbiditos Nicarã por erosão. Associam-se arenitos arcoseanos, friáveis, com níveis centimétricos de conglomerados com seixos de arenito e de quartzo leitoso, cujas EGAs de médio a grande porte $(1,0$ a 3,0 m) sugerem uma deposição eólica associada a canais fluviais temporários. Em direção ao topo, ocorrem arenitos finos com geometria de lobos sigmoidais. Drapes e /asers ocorrem entre os cosets. Seguem arenitos muito finos interlaminados com folhelhos com marcas onduladas e bioturbação, sugerindo um ambiente deposicional transicional e possivelmente marinho raso. Esta fácies evidencia uma transgressão de provável extensão regional da unidade Uailã.

Caracterizada pela presença marcante de níveis piroclásticos (tufos e ignimbritos ácidos) e vulcanoclásticos, a Formação Uailã é representada por uma sucessão onde se intercalam camadas arenosas e conglomeráticas, com mergulhos na ordem de $5^{\circ} \mathrm{NE}$. Este pacote tem sido interpretado como depositado em ambiente deltaico-marinho raso, como sugerem as fácies fluvial, eólica, de maré e barras costa afora (Fig. 4).

Dois setores distintos, oeste e leste (Fig. 4a e 4b), estão representados pela maior ou menor presença de uma sedimentação marinha na porção deltaica, possivelmente delimitando uma linha de costa. As estruturas sedimentares são preferencialmente corpos sigmoidais em sets métricos, com associação de EGAs, estruturas hummocky e mega-ripples formados por ação de ondas. Ritmitos com gradação maciço/laminado e possíveis estruturas herringbone ocorrem na seqüência. A presença de depósitos de surgência piroclástica foi descrita por Costi et al (1988), sugerindo a existência de uma caldeira de colapso na área.

A área de afloramento da Formação Matauí situa-se no domínio do monte Roraima e seus ambientes deposicionais incluem o transicional (inframaré) e o continental eólico e fluvial entrelaçado (Fig. 5). As rochas características são arenitos bem estratificados, com ECAs bidirecionais, corpos sigmoidais e possíveis sand waves. Encimam esta seqüência quartzo arenitos finos a muito finos, bem selecionados, com laminação planoparalela e marcas onduladas simétricas. O topo da seqüência consiste de arenitos médios a grossos, 
(4a)

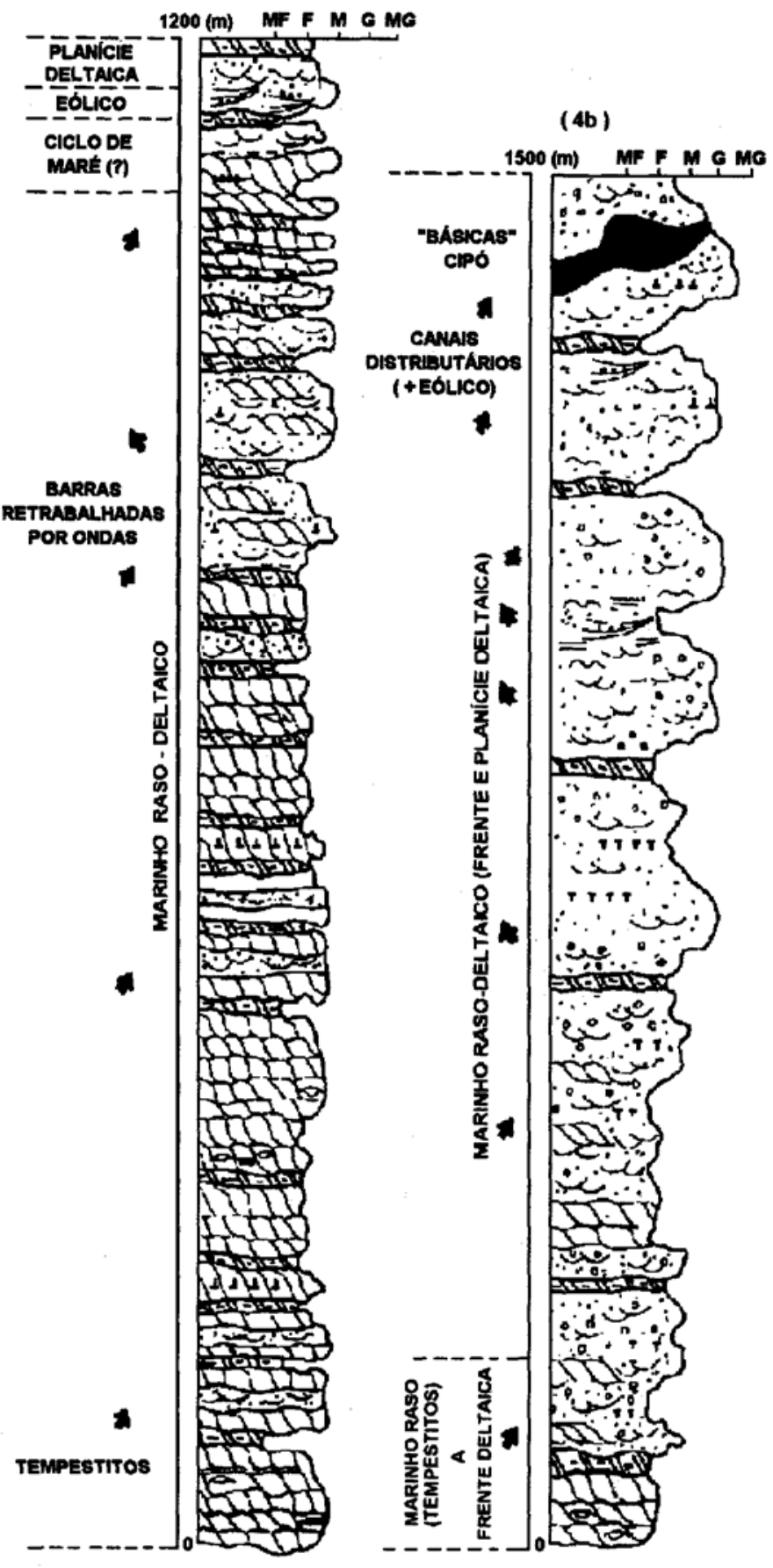

Figura 4 - Seções esquemáticas da Formação Uailã (a e b) do Super grupo Roraima (Pinheiro et al. 1990). Símbolos como no figura 2.

Figure 4 - Schematic sections of the Uailã Formation of the Roraima Supergroup (Pinheiro et ai. 1990). Symbols as in figure 2.

arenitos conglomeráticos e lentes de conglomerado, com EGAs em estruturas festonadas.

Existe uma íntima relação entre a evolução dos diferentes sistemas deposicionais e as fases de movimento da bacia, com evidências de produtos litoestruturais das fases tectônica (Formação Arai, Grupo Suapi e Formação Uailã) e termal (Formação Matauí) da borda meridional do Bloco Pacaraima em território brasileiro (Sena Costa, J.B. In: Pinheiro et al. 1990, capítulo 3). As rochas sedimentares estão fortemente contro-

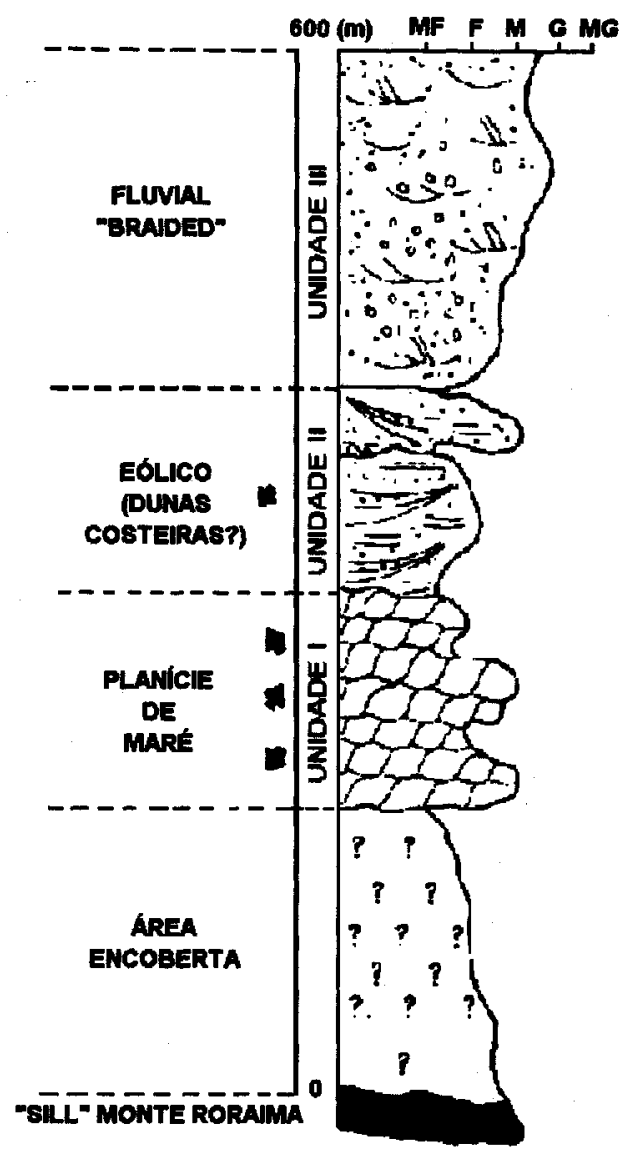

Figura 5 - Seção esquemática da Formação Matauí do Super grupo Roraima (Pinheiro et al. 1990). Símbolos como na figura 2.

Figure 5 - Schematic section of the Matui Formation of the Roraima Supergroup (Pinheiro et al. 1990). Symbolsras in figure 2.

ladas por extensas falhas WNW-ESE e NE-SW, com complexo sistema de planos de cisalhamento $\mathrm{N} 60^{\circ} \mathrm{W}$ com mergulhos de $60^{\circ} \mathrm{SW}$. A bacia que acolheu a sedimentação naquela porção, experimentou inversão positiva fraca a moderada a partir de uma compressão regional, onde os mergulhos das camadas para NE da seqüência basal contrastam com as direções de paleocorrentes do sistema fluvial para sul. Fraga et al. (1994) relatam a ocorrência de zonas de cisalhamento na borda sul do $\mathrm{BP}$, com cinemática de cavalgamento em arranjo de rampa frontal, resultante da inversão da bacia e as relacionam ao Episódio K'Mudku, do Mesoproterozóico.

Serra Tepequém Esta exposição sedimentar é um testemunho isolado, com cerca de $70 \mathrm{~km}$, e altitude máxima de 1000 m, situado na porção nor-nordeste de Roraima, a sul do baixo curso do rio Amajari (Folha NA.20-X-A-III). O conhecimento dos seus aspectos geológicos foi, em grande parte, obtido pelo seu conteúdo de ouro e diamante.

Borges \& D'Antona (1988) realizaram o estudo mais acurado de sua estratigrafia, propondo a correlação deste pacote sedimentar com a Formação Arai do BP, e subdividindo-o, da base para o topo, nos membros Paiva, Funil e Cabo Sobral. O substrato desta unidade consiste de rochas vulcânicas ácidas a intermediárias do Grupo Surumu.

O Membro Paiva é representada por conglomerados polimíticos, com seixos de rochas vulcânicas e arenitos em matriz argilosa. $\mathrm{O}$ topo da unidade é dominado por arenitos 
grossos a conglomeráticos com estratificação cruzada e estruturas de corte-e-preenchimento. As camadas apresentam atitude entre $\mathrm{N} 35-65^{\circ} \mathrm{E}$ e mergulhos de $5-25^{\circ}$ para $\mathrm{NW}$ ou SE. Uma discordância litológica e erosiva é sugerida para o contato entre a unidade sedimentar basal e as rochas vulcânicas Surumu.

Membro Funil é uma seqüência interacamadada de arenitos finos, siltitos e argilitos (Membro Funil), com estratificação cruzada acanalada e gretas de contração. Já o Membro Cabo Sobral compreende arenitos grossos conglomeráticos com intercalações de conglomerados.

A espessura do pacote sedimentar foi estimada em $210 \mathrm{~m}$ e seus membros são concordantes. Borges \& D'Antona (1988) interpretam o pacote como resultante da deposição em leques aluviais, dunas e sistema fluvial entrelaçado, mas sugere-se que o Membro Funil represente uma fácies lacustre (Fig. 6).

Sena Costa et al. (1991) interpretam a Serra Tepequém como uma klippe de cavalgamentos com vergência para sul. Posteriormente, Fraga \& Reis (1994) descrevem uma clivagem espaçada com forte mergulho para sul e definida por filmes de sericita e opacos nos psefitos da borda norte da serra. Esta clivagem é refratada nos pelitos, onde se observam manchas de redução achatadas paralelamente a uma clivagem ardosiana, planoaxial a microdobras fechadas. Uma foliação milonítica com mergulho de $70-80^{\circ}$ para norte e sul ocorre, respectivamente, nas rochas vulcânicas das bordas sul e norte da serra. As camadas estão dobradas em sinformais e antifor- mais abertos, com eixos na direção E-W a ENE-WSW. Este arranjo estrutural foi sugerido por Fraga \& Reis (1994) como resultante do desenvolvimento de feixes de cavalgamento ocorrido durante o Episódio K'Mudku, imprimindo textura milonítica nas rochas vulcânicas e dobras e clivagens nas sedimentares.

Serras Uafaranda e Urutanim Representam duas exposições de rochas sedimentares que sustentam platôs limitados por paredões abruptos, em muitos casos, blocos tectonicamente basculados como indicam os mergulhos dos estratos em todas as direções. As serras situam-se na região do alto curso do rio Urariqüera, em parte da Folha NA.20-V-B e NA.20-X-A, sendo que a serra Urutanim (cota de $1200 \mathrm{~m}$ ) é um trecho de fronteira entre o Brasil e a Venezuela. A serra Uafaranda está limitada, a sul e a norte, por falhas NW e SE de natureza desconhecida que estruturam um padrão regional romboédrico.

O conhecimento estratigráfico das rochas sedimentares destas áreas baseia-se em Montalvão et al. (1975) e, principalmente, nos resultados do mapeamento executado por Pinheiro et al. (1981) na porção ocidental do Estado de Roraima. Em geral, a escassez de dados resulta das dificuldades de acesso à região. Os autores agruparam estas rochas sedimentares no Grupo Roraima e Pinheiro et al. (1981) subdividiramno, da base para o topo, nas formações Tucuxumã, Aliquelau, Linepenome e Urutanim, em base a critérios de campo e

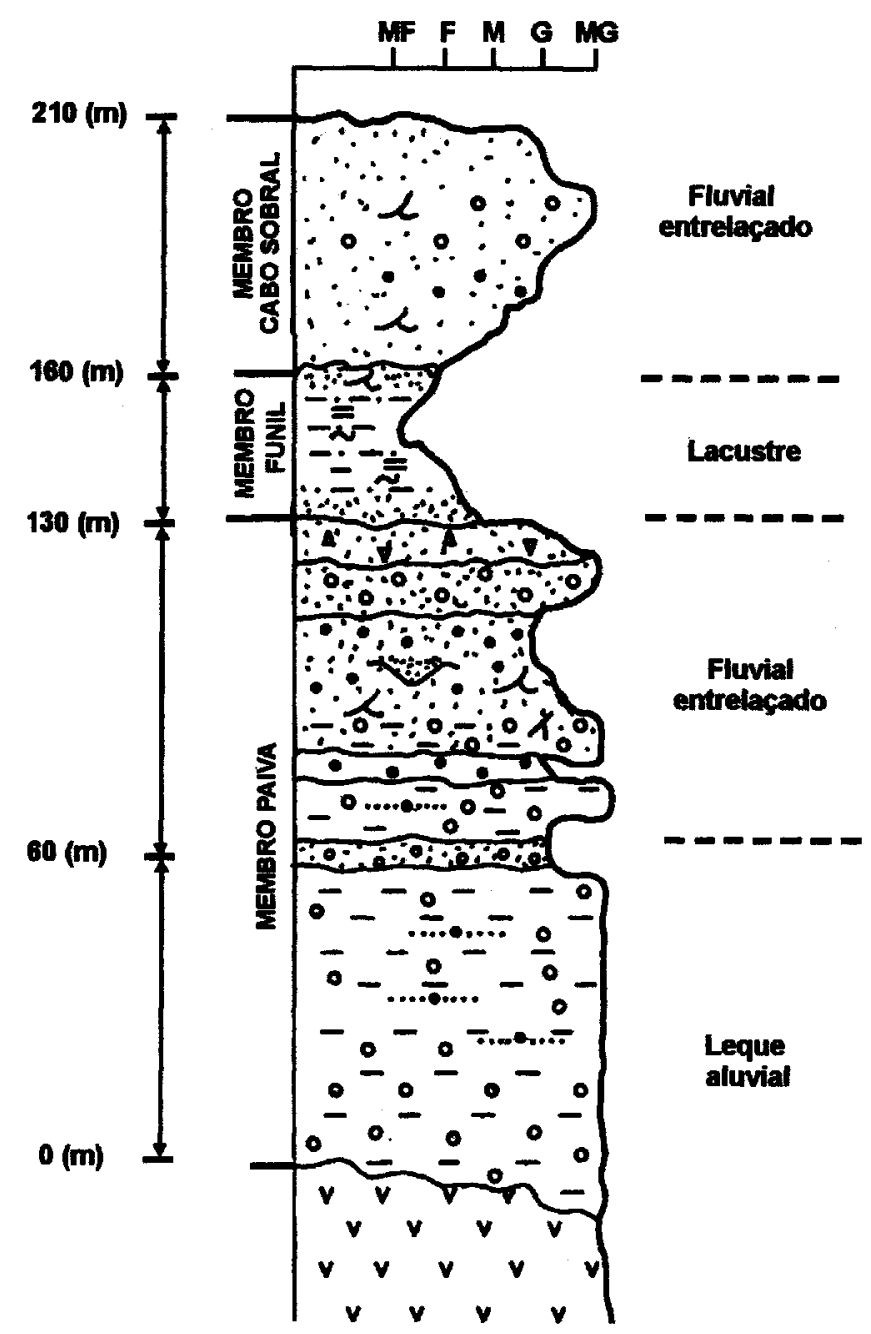

GRANULOMETRIA

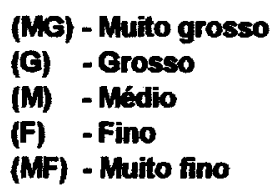
conglomerado(matriz argilosa)

A.7. brecha intraformacional arenito conglomerático

$\because:$ arenito

\section{ESTRUTURAS SEDIMENTARES}

\section{$\angle$ Estratificaça cruzada acanalada}

ᄉ Estratificagăo cruzada tabular

$\sim$ Marca ondulada

= Laminaça planoparalela

Corte e preenchimento

Figura 6 - Seção esquemática da Formação Tepequém na Serra homônima, adaptada da descrição de Borges \& D'Antona (1988). Figure 6 - Schematic section of the Topequém Formation, modified after Borges \& D'Antona (1988). 
fotogeológicos. Nenhuma subdivisão estratigráfíca do Grupo Roraima anterior pode ser precisamente correlacionada com as unidades propostas.

Regionalmente, estas rochas sedimentares assentam sobre um substrato composto por granitóides da Suíte Intrusiva Saracura, rochas vulcânicas do Grupo Surumu e terrenos granito-gnáissicos da Suíte Metamórfica Urariqüera. Dois sills da unidade Diabásio Avanavero ocorrem na serra Urutanim, enquanto diques básicos da mesma unidade secionam as rochas sedimentares da serra Uafaranda. As unidades Tucuxumã, Aliquelau e Linepenome foram definidas em grande parte ao longo da serra Uafaranda, com a Formação Urutanim tendo sido definida na serra homônima.

As rochas sedimentares mais basais (Formação Tucuxumã) são quartzo arenitos finos a médios, bem selecionados, com marcas onduladas simétricas e EGAs de pequeno a médio porte. Apesar da ocorrência de arenitos conglomeráticos e conglomerados na seção inferior da serra Urutanim, estes não foram incluídos nesta formação, uma vez que não ocorrem na localidade-tipo. Os termos conglomeráticos possuem seixos pouco retrabalhados e imbricados de rocha vulcânica, gnaisses e de quartzo leitoso. Em direção ao topo, afloram arenitos arcoseanos com fragmentos pelíticos achatados e ovais.

A Formação Aliquelau consiste de espesso pacote de folhelhos carbonosos, siltitos e argilitos interacamadados e que retratam uma mudança drástica de ambiente oxidante para redutor. Estas rochas assentam diretamente sobre quartzo arenitos e níveis de conglomerados intraformacionais, dentre os quais alguns são arenitos grossos com cimento manganesífero e com pequenas inclusões de folhelho carbonoso. Souza et al (1980) especularam que o contexto deposicional desta formação foi o de uma bacia restrita e estimaram que sua espessura é da ordem de $110 \mathrm{~m}$. O acamadamento desta unidade tem atitudes $\mathrm{N} 15-65^{\circ} \mathrm{E} / 45-55^{\circ} \mathrm{NW}$ a N20 $0^{\circ} \mathrm{W} / 40^{\circ} \mathrm{NE}$.

A Formação Linepenome é composta por uma seqüência de arenitos líticos, arcoseanos, conglomeráticos, siltitos e conglomerados. Sua geometria inclui pacotes maciços a estratificados com EGAs de pequeno a médio porte.

A Formação Urutanim ocorre como mesas na serra homônima, mas as informações de campo acerca da mesma são escassas. A rocha dominante desta unidade são quartzo arenitos com marcas onduladas e EGAs de grande porte. Uma soleira básica encontra-se próximo do contato com a Formação Linepenome.

Com a retomada dos trabalhos de campo no setor oeste de Roraima, no início da década de noventa, Reis (1991) realizou um estudo fotointerpretativo da serra Urutanim e adjacências. $\mathrm{O}$ autor dividiu a seqüência da região em três unidades informais (Fig. 7) que, da base para o topo, compreendem:

Unidade A - arenitos com intercalações de níveis conglomeráticos;

Unidade B - pelitos com uma soleira básica, e

Unidade C - quartzo arenitos arcoseanos interacamadados com termos conglomeráticos, com soleira básica.

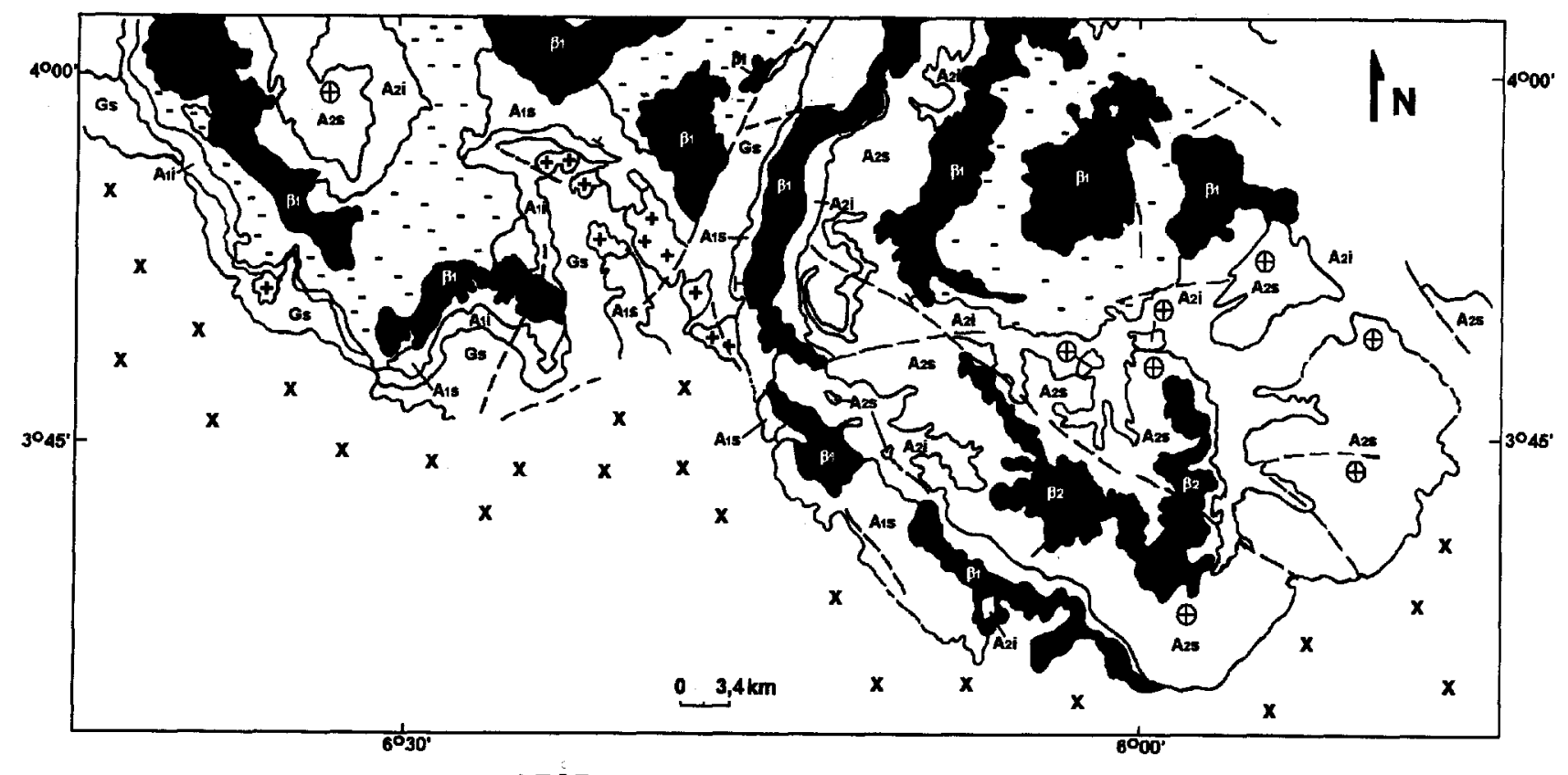

Unidade C (topo)

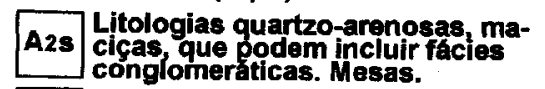
ciças, que podem incluir

$\beta_{2}$

"Sill" superior (Diab. Avanavero)

A2i Litologias quartzo-arenosas com calados. Vales profundos.
Unidade B

-- Essencialmente rochas peliticas tais como siltitos, folhelhos, argilitos, aren

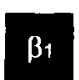

"Sill" inferior (Avanavero)

Pelitos de lapa do "sill"
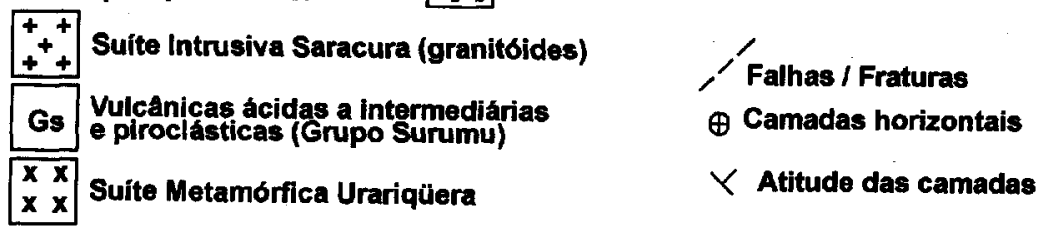

Unidade A

Litologias quartzo-arenosas com possiveis niveis conglomeraticos.

A1i Litologias arenosas

Figura 7 - Esboço fotogeológico da Serra Urutanim e adjacências (Reis 1991).

Figure 7 - Photogeological sketch of the Urutanim range area and surroundings (Reis 1991). 
As estruturas sedimentares e os tipos de rochas da serra Uafaranda permitem interpretar a seqüência como tendo sido depositada em ambientes continentais de leque aluviais e lacustre.

Serra das Surucucus Esta seqüência sedimentar assenta discordantemente sobre granitos da suíte Surucucus (1.5 Ga), terrenos granito-gnáissicos da Suíte Metamórfica Urariqüera e rochas supracrustais da Suíte Metamórfica Parima. Situa-se na porção mais oriental de Roraima, na área da Folha NA.20-V-D-II.

Trabalhos pioneiros são creditados a Montalvão et al. (1975) e Pinheiro et al. (1981). Reis et al. (1991) identificaram três fácies nas rochas sedimentares da serra das Surucucus, denominadas de (i) fácies de leque aluvial sustentada por clastos, (ii) fácies de canais de enxurrada e (iii) fácies de arenitos sílticos de águas rasas, e interpretadas como o registro de um ambiente deposicional exclusivamente continental de leques aluviais e lacustre (Fig. 8).

A fácies de leque aluvial sustentada por clastos é representada por um espesso pacote de conglomerados polimíticos

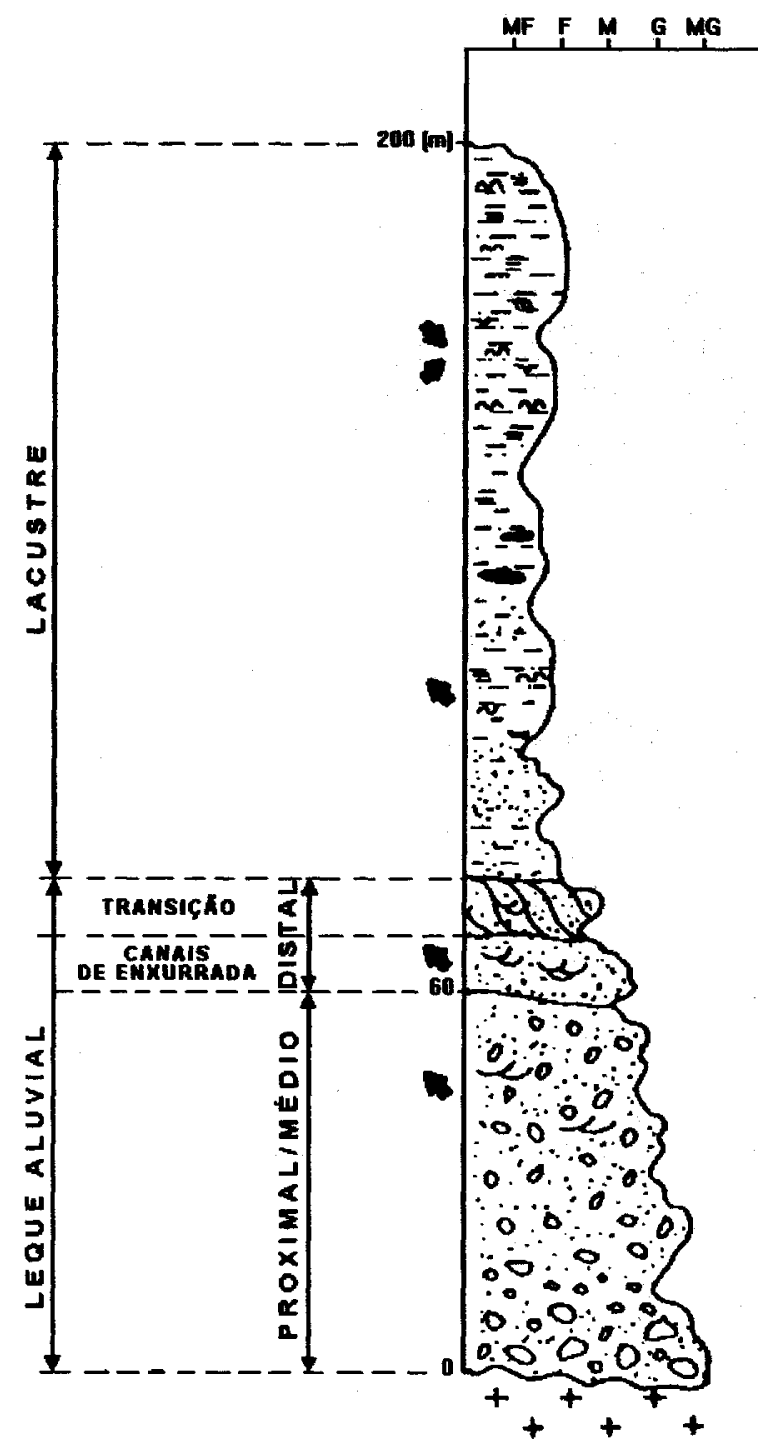

Figura 8 - Seção esquemática das rochas sedimentares da Serra das Surucucus (Reis et al. 1991). Símbolos como na figura 2.

Figure 8 - Schematic section of the sedimentary sequence of the Surucucus Mountain (Reis et al. 1991). Symbols as in figure 2. com seixos, calhaus e blocos de granito, rocha metavulcânica e gnaisse em matriz argilosa a arenosa fina. A abundância de fragmentos de granito sugere uma fonte proximal vinculada à Suíte Surucucus. Níveis métricos de quartzo arenito intercalam-se com os conglomerados, formando sítios de EC As de médio porte, em torno de $1,0 \mathrm{~m}$, com estruturas primárias que indicam paleocorrentes dirigidas para NW.

A fácies de canais de enxurrada (distai do leque aluvial) é pouco desenvolvida devido a proximidade da bacia receptora lacustre, com perda de possança do leque e restrição de ocorrência. A interação dos leques com o ambiente lacustre é notada pela presença de fluxos canalizados, via de regra obstruídos pelas variações do nível d'água, resultando em intercalações de material de granulação mais grossa do leque (fluxo de detritos retrabalhados) com depósitos arenosos sílticos da bacia de inundação. Estes níveis constituem material intraformacional contendo diminutos fragmentos de granito e arenito com abundante caulim. Alguns autores (e.g., Pinheiro et al. 1981, Santos 1982) interpretam estas intercalações como produtos da alteração de veios ígneos concordantes.

Neste set de arenitos quartzosos e conglomeráticos ocorre um padrão de ECAs de pequeno a médio porte $(0,5 \mathrm{a} 1,0 \mathrm{~m})$ que indicam paleocorrentes para NW. Acima, ocorrem quartzo arenitos em lobos sigmoidais, cujo topo e base apresentam níveis centimétricos caolinizados com grãos de quartzo e fragmentos e raros seixos de granito alterado. Todo o conjunto é interpretado como produto da deposição em condições ambientais de transição entre a porção distai dos leques aluviais e o lacustre.

A fácies de arenitos sílticos de águas rasas (lacustre) possui grande distribuição em área na região de Surucucus. Esta fácies situa-se estratigraficamente acima dos quartzo arenitos sigmoidais e é constituída de uma espessa seqüência de siltitos, arenitos sílticos e feldspáticos e quartzo arenitos, cujas principais estruturas compreendem marcas onduladas assimétricas, marcas onduladas simétricas bifurcadas e gretas de contração. Lentes pouco espessas de siltito carbonoso entremeiam-se a arenitos sílticos, aparentemente como bolsões.

A cobertura sedimentar de Surucucus não evidencia sinais de inversão, e as direções de paleocorrentes, notadamente para NW, são concordantes com os mergulhos das camadas $\left(\mathrm{N} 20 \mathrm{E} / 10^{\circ} \mathrm{NW}\right)$. A presença de uma significativa quantidade de seixos e calhaus de granitos da suíte Surucucus (tipo Parguaza) nos conglomerados de leques aluviais indica erosão e sedimentação após o evento intrusive.

ASPECTOS ECONÔMICOS A atividade extrativa mineral de grande parte das áreas sedimentares investigadas restringe-se à garimpagem de diamante e ouro, praticada por civilizados e índios aculturados nas aluviões e terraços fluviais de rios e igarapés que drenam aquelas bacias.

As dificuldades legais da região de Roraima por ser fronteira com a Venezuela e a Guiana e reserva indígena das tribos lanomami e Raposa/Serra do Sol, além dos empecilhos naturais de acesso e infra-estrutura na sua porção ocidental, constituem as principais interferências para a atividade garimpeira. As bacias dos rios Quinô/Suapi, Cotingo, médio rio Mau, a região do Uiramutã (bloco Pacaraima) e a serra Tepequém ainda são as mais exploradas, com registro de garimpes desde o início do século, mas sem controle permanente da produção de diamante e ouro. Nas serras Uafaranda e Surucucus não há evidências de ocorrência de diamantes e poucos dados referem-se à exploração de ouro. $\mathrm{Na}$ região oriental da serra Urutanim foi realizada alguma atividade de extração de ouro e diamante, particularmente nos rios Surubai e Ericó, cujas nascentes situam-se naquela serra. Indícios indiretos (geofísicos), apontam para mineralizações em U e U-Th em diversas porções do BP, com destaque para a região 
da serra Verde (Folha NB.20-Z-D-II) e onde a garimpagem para ouro é realizada em pelitos da Formação Verde do Grupo Suapi.

Os resultados de análises químicas de rochas carbonosas da serra Uafaranda foram pouco promissores, com indicação de teores de cinza extremamente elevados e baixo poder calorífíco.

DISCUSSÃO A idade mínima de formação atribuída à cobertura sedimentar do Mesoproterozóico do Escudo das Guianas, tem sido expressa através de dados geocronológicos das soleiras básicas da unidade Diabásio Avanavero e em rochas piroclásticas ácidas que se intercalam em algumas seqüências (e.g., Bloco Pacaraima, Tafelberg no Suriname, Urupi no Estado do Amazonas). Os granitos mais jovens da suíte Surucucus têm sido sistematicamente interpretados por alguns autores (e.g., Santos 1978, Santos \& Pinheiro 1981, Santos 1982) como intrusivos em parte da seqüência sedimentar inferior. Sob o aspecto da época do início da sedimentação, a idade $\mathrm{Rb} / \mathrm{Sr}$ de $1789 \mathrm{Ma}$ obtida para as intrusões da suíte Saracura (Santos \& Reis Neto 1982) tem servido de parâmetro a sua idade máxima, apesar das relações de campo entre a cobertura e os granitos serem duvidosas, e se existentes, escassas. Ademais, no caso do BP, toda sua porção meridional assenta sobre rochas vulcânicas do Grupo Surumu, por sua vez secionada pelos granitos Saracura, em áreas que não possuem coberturas sedimentares.

Nos últimos anos, estudos petroquímicos e geocronológicos têm demonstrado, respectivamente, um caráter cogenético entre as rochas vulcânicas e os corpos intrusivos do final do Ciclo Transamazônico (Dall'Agnol et al 1987, Reis \& Fraga 1996) e idades U/Pb em zircão de $1.96 \mathrm{Ga}$ e, portanto, do Paleoproterozóico (Schobbenhaus et al. 1994). Estes dados levam a novas interpretações sobre a idade máxima da sedimentação, do limite de tempo entre o Meso e Paleoproterozóico e novas considerações sobre o fechamento da Orogenia Transamazônica.

$\mathrm{Na}$ serra das Surucucus, as rochas sedimentares assentam discordantemente sobre granitos com idade $\mathrm{Rb} / \mathrm{Sr}$ de $1542 \mathrm{Ma}$ (Basei \& Teixeira 1975), em contraste com as idades mais antigas de 1602 Ma e de 1635 Ma obtidas nos sills Avanavero da Guiana respectivamente por Hebeda et al. (1973) e McDougall et al. (1973), e de $1655 \pm 18 \mathrm{Ma}$ e $1731 \pm 49$ Ma obtidas, respectivamente, por Priem et al. (1973) e Gaudette \& Olszewski (1981) em rochas piroclásticas ácidas interestratificadas no Membro Tafelberg no Suriname e na Venezuela e na porção mediana do Supergrupo Roraima do Bloco Pacaraima, equivalente à Formação Uailã no Brasil (Pinheiro et al. 1991), Formação Uaimapué na Venezuela (Reid 1972) e Unidade IX na Guiana (Keats 1973).

Uma amostra de saprólito de arenito conglomerático da Formação Arai apresentou idade U/Pb em zircão de $2171 \pm$ $16 \mathrm{Ma}$, sugerindo uma área-fonte de idade transamazônica (Gaudette et al. 1996).

A borda norte do BP é dominada por terrenos greenstone de idade Transamazônica (supergrupos Barama-Mazaruni da Guiana e Pastora-Carichapo da Venezuela), que tiveram importância como fonte elástica na formação do BP no início do Mesoproterozóico. As direções de paleocorrentes, de norte para sul, obtidas no grande sistema fluvial da porção basal do BP (Pinheiro et al. 1990) se coadunam com os dados geocronológicos.
A extensa distribuição, em aproximadamente 1.200.000 $\mathrm{km}^{2}$, das exposições sedimentares do Mesoproterozóico do Escudo das Guianas, tem conduzido vários pesquisadores a discutir se as ocorrências representam remanescentes de uma única bacia ou vários sítios sedimentares isolados. Pela sua magnitude, é provável que houveram várias bacias, de dimensões e idades variadas, cuja sedimentação, nem sempre contemporânea, ocorreu sobre diferentes embasamentos e registros deposicionais diversificadas em função das áreas-fonte e do condicionamento tectônico local que propiciaram regimes deposicionais distintos no Brasil, Venezuela, Guiana e no Suriname.

Quando correlacionadas, devem ser compreendidas apenas com base na evolução do Escudo das Guianas e sua resposta sobre os vários sistemas deposicionais continental e transicional/marinho, este constituindo-se de um excelente nível guia no registro regressivo-transgressivo do mar, em resposta às diversas etapas tectônicas de seu desenvolvimento. Assim, as seqüências sedimentares do Bloco Pacaraima e das serras Tepequém, Uafaranda, Urutanim e Surucucus, não devem ser prontamente correlacionadas sob a designação única Roraima. Gibbs \& Barron (1993) propuseram o termo QuasiRoraima para designar os vários sítios deposicionais do Mesoproterozóico.

CONCLUSÕES As relações cronológicas com o embasamento diverso (rochas vulcânicas, granitos e gnaisses) e as rochas intercaladas (sills básicos e rochas piroclásticas) nas seqüências sedimentares mesoproterozóicas do Estado de Roraima demonstram que a deposição nas bacias Surucucus, Urutanim, Uafaranda, Tepequém e no Bloco Pacaraima (BP) ocorreu em tempos diferentes. $\mathrm{O}$ retrabalhamento de granitos em 1.5 Ga da região de Surucucus durante a deposição de conglomerados basais indica uma deposição tardia em aproximadamente $100 \mathrm{Ma}$, se comparada a idade mínima de $1.6 \mathrm{Ga}$ das rochas básicas Avanavero intercaladas nas sedimentares do BP.

A interpretação das seqüências sedimentares da serra das Surucucus e, em parte, também daquelas das serras Uafaranda, Urutanim e Tepequém como continentais leva à conclusão de as mesmas registrarem sistemas de sedimentação em bacias restritas. Isto reduz a probabilidade de constituírem variações laterais de fácies da seqüência que ocorre no BP, caracterizado por uma sedimentação marinha e ausência de expressiva sedimentação carbonosa.

A presença de soleiras básicas e de rochas piroclásticas, por exemplo no BP, indicam que a sedimentação em determinados sítios foi acompanhada de atividade vulcânica.

A idade U/Pb em zircão de $1.96 \mathrm{Ga}$ e a afinidade química com granitóides do final do Ciclo Transamazônico das rochas vulcânicas Surumu, sugere que as rochas sedimentares do Bloco Pacaraima são mais antigas do que atualmente considerado.

$\mathrm{O}$ arcabouço estrutural exposto nas diversas exposições sedimentares do Mesoproterozóico, foi produzido por reativação de estruturas mais antigas, aindajião totalmente compreendidas no Escudo das Guianas. A exceção do bloco Pacaraima e da serra Tepequém, não há sinais aparentes de inversão das seqüências sedimentares das serras Uafaranda, Urutanim e Surucucus, decorrentes de regimes tectônicos compressivos regionais do final do Mesoproterozóico (Evento K'Mudku).

\section{REFERENCIAS}

AGUERREVERE, S.E.; LÓPEZ, V.M.; DELGADO, O.C. \& FREEMAN, C. A. 1939. Exploration de La Gran Sabana. Rev. de Fomento, 3(19): 501-729.
BASEI, M.A.S. \& TEIXEIRA, W. 1975. Geocronologia do Território de Roraima. In: CONFERÊNCIA GEOLÓGICA INTERGUIANAS, 9 Belém, 1975. Anais... Belém, MME/DNPM, p. 453-473. 
BORGES, F.R \& D'ANTONA, R. de J.G. 1988. Geologia e mineralizações da serra Tepequém. In: CONGRESSO BRASILEIRO DE GEOLOGIA, 35, Belém, 1988. Anais... Belém, SBG, Núcleo Norte, v.1.p. $155-163$.

BOUMAN, Q.C. 1959. The Roraima Formation, northern of Território do Rio Branco. Belém. PETROBRÁS/RENOR, 17 p. (Relatório Interno 350-A).

CASTRO, J.C. de \& BARROCAS, S.L.S. 1986. Faciés e ambientes deposicionais do Grupo Roraima. Rio de Janeiro, PETROBRÁS/CENPES, 20p., il.

COSTI, H.T.; PINHEIRO, S. da S. \& REIS, NJ. 1988. Rochas piroclásticas da Formação Uailã, Supergrupo Roraima, Território Federal de Roraima. In: CONGRESSO BRASILEIRO DE GEOLOGIA, 35, Belém, 1988. Anais.... Belém. SBG, Núcleo Norte, v.3, p. 1339-1348.

DALTON, L.V. 1912. On the geology of Venezuela. Geol.Mag., London, England, 9: 203-210.

DALL'AGNOL, R.; BETTENCOURT, J.S.; JORGE JOÃO, X.da; MEDEIROS, H.de; COSTI, H.T. \& MACAMBIRA, M.J.B. 1987. Granitogenesis in northern brazilian region: a review. Revista Brasileira de Geociencias 17: 382-403.

FRAGA, L.M.B.; REIS.N.J. \& PINHEIRO, S. da S. 1994. Arranjo estrutural do segmento sul do bloco Pacaraima, Estado de Roraima. In: SIMPOSIO DE GEOLOGIA DA AMAZÔNIA, 4, Belém, 1994. Anais... Belém, SBG, Núcleo Norte, p. 7-9.

FRAGA, L.M.B. \& REIS, N.J. 1994. Serra Tepequém - Uma estrutura relacionada à inversão da Bacia Roraima. In: CONGRESSO BRASILEIRO DE GEOLOGIA, 38, Camboriú, 1994. Resum.Exp.... Camboriú. SBG/DNPM/CPRM, v.2, p. 294-295.

GAUDETTE, H.E \& OLSZEWSKI JR., W.J. 1981. Determination of radiometric ages, Amazonas Territory, Venezuela. In: SIMPOSIUM AMAZÔNICO, 1, Venezuela, 1981. Memória...Venezuela. Direción General Sectorial de Minas y Geologia. (Boletin 10), p. 733-746.

GAUDETTE, H.E., OLSZEWSKI JR., W.J. \& SANTOS, J.O.S. 1996. Geochronology of Precambrian rocks from the northern part of the Guiana Shield, State of Roraima, Brasil. Journal of South American Earth Sciences, (in press)

GHOSH, S. K. 1977. Geologia del Grupo Roraima en Território Federal Amazonas, Venezuela. In: CONGRESSO GEOLÓGICO VENEZOLANO, 5, Caracas, 1977. Memorâ...Caracas, Ministério de Minas y Hidrocarburos, p. 167-193.

GIBBS, A.K. \& BARRON, C.N. 1983. The Guiana Shield Reviewed. Episodes, 2: 7-14

GIBBS, A.K. \& BARRON, C.N. 1993. The Geology of Guiana Shield. Oxford Monographs on Geology and Geophysics. Oxford University Press, New York, 2:246p.

HEBEDA, E.H.; BOELRIJK, N.A.I.M.; PRIEM, H.N.A.; VERDURMEN, E.A. Th. \& VERSCHURE, R.A. 1973. Excess radiogenic argon in the Precambrian Avanavero Dolerite in western Surinam (South America). Earth Planetary Science Letters. 20 (2): 189-200.

KEATS, W. 1973. The Roraima Formation in Guyana: A revised stratigraphy and a proposed environment of deposition. In: CONGRESSO LATINOAMERICANO GEOLÓGICO, 2, Caracas, 1973. Memória... Caracas, Ministério de Minas y Hidrocarburos, (Boletin Especial, 7) p. 901-940.

Mc DOUGALL, I.; COMPSTOM, W. \& HAWKES, D.D. 1973. Leakage of radiogenic argon and strontion from minerals in proterozoic dolerites from British Guiana. Nature. 198: 564-567.

MONTALVÃO, R.M.G. de; MUNIZ, H.de B.; ISSLER, R.S.; DALL'AGNOL, R; LIMA, M.I.C de; FERNANDES, P.E.C.A. \& SILVA, G.G. da 1975. Geologia da folha NA.20-Boa Vista e parte das folhas NA.21-Tumucumaque, NB.20-Roraima e NB.21. In: BRASIL-DNPM. Projeto RADAMBRASIL. Folha NA.20-Boa Vista e parte das folhas NA.21-Tumucumaque, NB.20-Roraima e NB.21. Rio de Janeiro, 1975. il. (Levantamento de Recursos Naturais, 8).

PINHEIRO, S. da S.; NUNES, A.C.B.; COSTI, H.T.; YAMAGUTI, H.S FARACO, M.T.L.; REIS, N.J.; MENEZES, R.G. de; RIKER, S.R.L. \& WILDNER, W. 1981. Projeto Catrimani-Urariqüera. Relatório Final. Manaus, DNPM/CPRM, v.I-A, il.

PINHEIRO, S. da S.; REIS, N.J. \& COSTI, H.T. 1990. Geologia da Região de Caburai. Relatório Final. Manaus, DNPM/CPRM, il., 91 p.

PRIEM, H.N.A.; BOELRIJK, N.A.I.M.; HEBEDA, E.H.; VERDUMEN, E.A. Th \& VERSCHURE, R.H. 1973. Age of Precambrian Roraima Formation in northeastern South America: Evidence from isotopic dating of Roraima pyroclastic volcanic in Surinam. Geol.Soc.Am.Bull, 84: 1677-1684.
REID, A. R. 1972. Stratigraphy of type area of the Roraima Group, Venezuela. In: CONFERÊNCIA GEOLÓGICA INTERGUYANAS, 9, Venezuela, 1972. Memória... Venezuela, Ministério de Minas y Hidrocarburos, Boletin de Geologia, Publ ,Esp. 6: p. 343-353.

REIS, N.J.; PINHEIRO, S. da S. \& CARVALHO, J.E. 1985. Subdivisão litoestratigráfica da Formação Suapi -Grupo Roraima - Território Federal de Roraima. In: SIMPÓSIO DE GEOLOGIA DA AMAZÔNIA, 2, Belém, 1985. Anais... Belém, SBG, Núcleo Norte, v.1, p. 408-420.

REIS, N.J; PINHEIRO, S da S · COSTI, H.T \& SENA COSTA, J.B. 1990. A cobertura sedimentar proterozóica média do Supergrupo Roraima no norte do Estado de Roraima, Brasil: Atribuições aos seus sistemas deposicionais e esquema evolutivo da sua borda meridional. In: CONGRESSO BRASILEIRO DE GEOLOGIA, 36, Natal, 1990. Anais... Natal, SBG, v.1, p. 66-81.

REIS, N.J.; SANTOS, J.O.S.; RIKER, S.R.L; PESSOA, M.R. \& PINHEIRO, S. da S. 1991. A cobertura sedimentar Roraima na serra das Surucucus - Enfoque a seus ambientes deposicionais. In: SIMPÓSIO DE GEOLOGIA DA AMAZÔNIA, 3, Belém, 1991. Anais... Belém, SBG, Núcleo Norte, p. 361-370.

REIS, NJ. 1991. Fotogeologia da serra Urutanim e adjacências Contribuição ao Projeto Parima. CPRM, SUREG-MA, Relatório Interno (sem identidade).

REIS, N.J. \& FRAGA, L.M.B. 1996. Vulcanismo Surumu - Estado de Roraima: Caracterização de seu comportamento químico à luz de novos dados. In: CONGRESSO BRASILEIRO DE GEOLOGIA, 3..., Salvador, 1996. Anais... Salvador, Bahia, SBG, v., p. 88-90.

SANTOS, J.O.S. 1978. Subdivisão do Pré-Cambriano da Amazônia: Uma sugestão. Acta Amazônica, 8: 267-287.

SANTOS, J.O.S. \& PINHEIRO, S. da S. 1981. Suíte Intrusiva Surucucus e a Reativação Parguazense (Petrologia). In: SIMPOSIUM AMAZÔNICO, 1, Venezuela, 1981. Memória... Venezuela. Direción General Sectorial de Minas y Geologia. (Boletin 10), p. 273-289.

SANTOS, J.O.S. 1982. Granitos proterozóicos da Plataforma Amazônica. CPRM/SUREG-MA, Relatório Inédito, 1Op.

SANTOS, J.O.S. \& REIS NETO 1982. Algumas idades de rochas graníticas do Cráton Amazônico. In:CONGRESSO BRASILEIRO DE GEOLOGIA, 32, Salvador, 1982. Anais... Salvador, SBG, v.1, p. 339 -348 .

SANTOS, J.O.S. \& D'ANTONA, R. de J.G. 1984. A Formação Arai e a subdivisão do Grupo Roraima. In: CONGRESSO BRASILEIRO DE GEOLOGIA, 33, Rio de Janeiro, 1984. Anais... Rio de Janeiro, SBG, Núcleo-RJ,p. 1162-1173.

SANTOS, J.O.S. 1985. A subdivisão estratigráfica do Grupo Roraima. In: SIMPÓSIO DE GEOLOGIA DA AMAZÔNIA, 2, Belém, 1985. Anais... Belém, SBG, Núcleo Norte, v.1, p. 421-431.

SCHOBBENHAUS, C.; HOPPE, A - BAUMANN, A \& LORK, A. 1994. Idade $\mathrm{U} / \mathrm{Pb}$ do magmatismo Uatumã no norte do Cráton Amazônico, Escudo das Guianas (Brasil): Primeiros Resultados. In: CONGRESSO BRASILEIRO DE GEOLOGIA, 38, Camboriú, 1994. Anais.. Camboriú, SBG/ DNPM/ CPRM, v.2, p. 395-397.

SENA COSTA, J.B. 1990. Geologia Estrutural. In: PINHEIRO.S.da S.; REIS, N.J. \& COSTI, H.T., Geologia da Região de Caburaí. p.55-58.

SENA COSTA, J.B.; REIS, N.J.; PINHEIRO, S. da S. \& PESSOA, M.R. 1991. Organização litoestrutural do Mesoproterozóico do Extremo Norte do Estado de Roraima. In: SIMPÓSIO DE GEOLOGIA DA AMAZÔNIA, 3, Belém, 1991. Anais... Belém, SBG, Núcleo Norte, p. 172-192.

SOUZA, M.M. de; PINHEIRO, S. da S. \& CAMOZZATO, E. 1980. Primeiras notícias da ocorrência de sedimentos carbonosos no Grupo Roraima. In: CONGRESSO BRASILEIRO DE GEOLOGIA, 31, Camboriú, 1980. Anais... Camboriú, SBG, v.5, p. 2996-3002.

YÁNEZ, G.A. 1972. Província geológica de Roraima; geologia estructural y geomorfologia de su parte septentrional entre los rios Paragua y Caroni (Venezuela). In: CONGRESSO GEOLÓGICO VENEZOLANO, 4, Caracas, 1972. Memória... Venezuela, Ministério das Minas y Hidrocarburos, Boletin 5, p.2122 - 2131.

Manuscrito A860 Recebido em 30 de setembro de 1996 Revisão dos autores em 29 de maio de 1997 Revisão aceita em 30 de maio de 1997 